\title{
Essential information about patterns of victimisation among children with disabilities
}

\section{Sherry Hamby, ${ }^{1}$ John Grych ${ }^{2}$}

10.1136/eb-2012-101106

${ }^{1}$ Department of Psychology, Sewanee, the University of the South, Sewanee, Tennessee, USA

${ }^{2}$ Department of Psychology, Marquette University, Milwaukee, Wisconsin, USA

Correspondence to: Dr Sherry Hamby Department of Psychology, Sewanee, the University of the South, 735 University Avenue, Sewanee, Tennessee 37383, USA;

sherry.hamby@sewanee.edu

Commentary on: Jones L, Bellis MA, Wood S, et al. Prevalence and risk of violence against children with disabilities: a systematic review and meta-analysis of observational studies. Lancet 2012;380:899-907.

\section{Implications for practice and research}

- Children with disabilities are at increased risk for virtually every type of violence that has been measured in this population.

- Healthcare providers and researchers need to take a more comprehensive, person-centered approach that focuses on the vulnerability to polyvictimisation and the interconnection among forms of violence for children with disabilities.

\section{Context}

Many forms of violence against children are all too common $^{1}$ and the health consequences are dramatic. One in ten experience a violence-related injury every year. ${ }^{2}$ Violence is a leading cause of death among youth, and is ranked the second leading among all causes for adolescents aged 15-19. ${ }^{3}$ Behind these global statistics, however, are particularly vulnerable subgroups of children. One of the most vulnerable subgroups is children with disabilities, but data on this group are limited and scattered. Accurate data on the extent of violence against children with disabilities, and any heightened vulnerability relative to other children are essential for sound intervention, prevention and policy. Jones and colleagues' systematic review compiles the best data on the prevalence and relative risk of violence among children with disabilities.

\section{Methods}

This careful and thorough systematic review involved the screening of more than 10000 references found from multiple online and hand searches of articles including terms related to disability and victimisation. More than 800 fulltext articles were reviewed, yet only 17 studies had usable data on the prevalence or relative risk of violence against children with disabilities. There were 16 that provided prevalence statistics, and 11 that had data on risk compared with children without reported disabilities. All the studies had been conducted in the USA or Europe, omitting many parts of the world with higher than average rates of both childhood disability and violence.

\section{Findings}

The prevalence of violence was disturbingly high, with more than 1 in 4 (27\%) youth with disabilities experiencing physical violence and more than 1 in $6(15 \%)$ experiencing sexual victimisation. Even more strikingly, children with disabilities were three to four times more likely to experience many types of violence than other children (ORs ranging from 2.88 to 4.56), including physical violence, sexual violence, emotional abuse and neglect. One particularly troubling finding is that the risk of sexual violence was significantly higher for children with psychological or intellectual disabilities compared with children with physical disabilities.

\section{Commentary}

The authors suggest that 'the extent of violence against children with disabilities might extend further than has been assessed'. It is crucial to go beyond assessing the prevalence of specific violence types to consider the interconnections among forms of violence if the true burden of victimisation is to be understood. ${ }^{1}$ As Jones and colleagues note, at the time of their review, only one study was available on bullying, and none on important forms of violence such as exposure to domestic violence. Almost all the studies they found focused on parental maltreatment, but parental maltreatment is strongly associated with many other forms of victimisation. Indeed, more than one-third of maltreatment victims are also 'polyvictims', youth who have been victimised in multiple ways, often by multiple perpetrators in multiple settings. ${ }^{4}$ More recently, nationally representative data have shown that the risks of peer victimisation and property crime are also elevated for children with disabilities. ${ }^{5}$

The problems of emotional, behavioural and physical disabilities illustrate a key point regarding the interconnections among forms of violence that persistent underlying vulnerabilities explain not only high rates of individual forms of violence, but also why most forms of violence are interrelated. ${ }^{1}$ These interconnections call for a shift from interventions that focus on particular violence types to person-centred approaches that comprehensively assess children's safety across settings. This change can guide future research and intervention on violence against children with disabilities. A first step would be broadening assessment and screening; regardless of the presenting problem, all children should be assessed about their safety in all key settings: home, school and neighbourhood.

Competing interests None. 


\section{References}

1. Hamby S, Grych J. The web of violence: exploring connections among different forms of interpersonal violence and abuse. Dordrecht, The Netherlands: Springer, 2013.

2. Finkelhor D, Turner H, Ormrod R, et al. Violence, abuse and crime exposure in a national sample of children and youth. Pediatrics 2009;124:1411-23.
3. Heron M. Deaths: leading causes for 2009. National vital statistics reports. vol 61. no 7. Hyattsville, MD: National Center for Health Statistics, 2012.

4. Turner H, Finkelhor D, Ormrod R. Poly-victimization in a national sample of children and youth. Am J Prev Med 2010;38:323-30.

5. Turner HA, Vanderminden J, Finkelhor D, et al. Disability and victimization in a national sample of children and youth. Child Maltreat 2011;16:275-86. 